\title{
ESCOLA E TRABALHO: UNIVERSITÁRIOS E ESTUDANTES DA EJA EM FOCO
}

\section{SCHOOL AND WORK: UNIVERSITY AND YOUNG AND ADULT STUDENTS ON FOCUS}

\author{
Marcio Luiz Bernardim*
}

\begin{abstract}
RESUMO
Este artigo apresenta os resultados de pesquisas realizadas com alunos do Ensino Médio da EJA e universitários de um município do interior do Paraná, com o objetivo de caracterizar socioeconomicamente os estudantes e investigar sua relação com a educação escolar. Foram aplicados questionários adaptados para cada um dos universos escolares e para cada grupo, segundo a condição de emprego/desemprego no momento da pesquisa. A análise dos dados foi feita a partir da compreensão da historicidade das relações entre a escola e o sistema produtivo e dos desafios enfrentados pelos estudantes-trabalhadores para a produção da sua existência material e imaterial.
\end{abstract}

Palavras-chave: Escola. Trabalho. Ensino Superior.

\begin{abstract}
This article presents the results of investigations carried out with high school (EJA, Education of Youth and Adults in the Portuguese acronym) and university students in a city in the Paraná State. The study aimed at developing the socioeconomical profile of the students and to verify their relation to school education. The investigation used questionnaires adapted for each of the school contexts and for each group according to the employment/unemployment situation at the moment of the research. The data analysis was made based on the comprehension of the historical aspects of the relations between school and the productive system in addition to the challenges that students-workers face in the provision of their material and non-material existence.
\end{abstract}

Keywords: School. Work. Higher Education.

\footnotetext{
" Professor do Departamento de Administração, Setor de Ciências Sociais Aplicadas, do Campus de Guarapuava, da UNICENTRO. E-mail: <marcio. bernardim@gmail.com>.
} 


\section{Introdução}

Este estudo se concentra na temática da juventude e suas relações com a educação escolar e o mercado de trabalho. A compreensão dos jovens e adultos, estudantes e trabalhadores, requer que sejam tomados a partir dos espaços de trabalho e de formação que ocupam na realidade objetiva deste início de século, marcada por um impulso à escolarização e, ao mesmo tempo, por relações de trabalho cada vez mais precárias.

A educação escolar ganhou impulso com as políticas que decorreram dos embates, verificados mais intensamente nas últimas três décadas entre forças progressistas e conservadoras no âmbito da sociedade brasileira. Os avanços relativos à universalização escolar de nível fundamental apresentam, agora, um novo desafio, relacionado à ampliação do acesso e melhoria da qualidade da educação escolar destinada aos jovens, seja no Ensino Médio, como última etapa da educação básica, seja na continuidade dos estudos em nível superior.

A aproximação com os estudantes que venceram a etapa da inserção universitária e com aqueles que decidiram voltar à escola para concluir a última etapa da Educação Básica (caso do Ensino Médio da Educação de Jovens e Adultos - EJA), foi o objetivo desta investigação. Esse movimento permitiria compreender a relação desses estudantes com a escola, seus anseios formativos e profissionais e seus projetos de futuro. Dessa forma, respeitados os limites de configuração metodológica, este artigo apresenta os resultados de pesquisas realizadas com o coletivo estudantil indicado, buscando contribuir para a análise da importância e da efetividade da educação escolar contemporânea.

Mediante uma oferta distribuída em diversos níveis e modalidades, de acordo com o que se entende adequado para atender às demandas sociais, a educação escolar se debate com um ambiente marcado por significativas mudanças estruturais, fluidez nas relações sociais e ressignificação das instituições.

As mudanças estruturais têm relação com a implementação tecnológica de base microeletrônica que impacta sobre a produção de bens e a prestação de serviços, em especial dos artefatos tecnológicos que revolucionam a geração, armazenamento e comunicação de dados e informações. As relações são influenciadas por essa mudança estrutural, que pode tanto encurtar as distâncias quanto segregar as proximidades, conforme se verifica na utilização massiva das redes sociais e dos sites de busca na internet. A ressignificação das instituições decorre da turbulência das mudanças na vida em sociedade e seus reflexos nos valores, na ética, na moral, e na percepção de utilidade das próprias instituições, o que pode determinar a sua relativização diante de determinadas situações da vida contemporânea.

A escola passa, nesse contexto, por um agudo processo de crítica e recebe um forte apelo para atender de forma mais rápida e eficaz aos interesses da sociedade, apresentando-se, assim, como uma instituição que carece de um esforço continuado de investigação.

\section{Análise e discussão dos dados empíricos}

Conforme já anunciado, este estudo objetivou caracterizar o público jovem inserido na Educação de Jovens e Adultos, EJA, e no Ensino Superior, analisando esse perfil de acordo com relações que esses sujeitos estabelecem com a escola e o mundo do trabalho. A primeira investigação foi realizada com 325 alunos de uma escola pública especializada na modalidade EJA, nos anos de 2005 e 2006. A segunda investigação foi realizada com 285 alunos de último ano de cursos de bacharelado e licenciatura de uma universidade pública, nos anos de 2009 e 2010. Ambas as unidades escolares estão localizadas em um município do interior do estado do Paraná com aproximadamente 170 mil habitantes. As investigações empíricas, embora independentes, fazem parte de uma pesquisa continuada que tem nas relações dos jovens e adultos com a escola e com o trabalho o seu objeto de estudo.

Os dois públicos responderam a um questionário composto de três blocos de perguntas: um para caracterização do perfil do respondente, constando de questões como faixa etária, domicílio e estado civil; um para caracterização socioeconômica, constando de questões sobre a condição de emprego/ desemprego e nível de renda; o último bloco com questões abertas destinadas a investigar a percepção dos alunos a respeito do trabalho, da educação e dos projetos futuros. 
No total da pesquisa, os dados sobre a idade dos alunos foram organizados de tal forma a proporcionar a segmentação etária no interesse do estudo em relação aos grupos pesquisados (da EJA e universitários), agrupando os estudantes em três faixas distintas:

Tabela 1 - Distribuição etária dos estudantes de Ensino Médio da EJA

\begin{tabular}{l|c|c|c}
\hline & Até 20 anos & $\begin{array}{c}21 \text { a 35 } \\
\text { anos }\end{array}$ & $\begin{array}{c}\text { Acima de } \\
35 \text { anos }\end{array}$ \\
\hline Número de Alunos & 64 & 150 & 111 \\
\hline$\%$ do Total & 19,69 & 46,16 & 34,15 \\
\hline
\end{tabular}

Fonte: Pesquisa de campo na EJA (2005/2006).

Tabela 2 - Distribuição etária dos estudantes universitários

\begin{tabular}{l|c|c|c}
\hline & Até 25 anos & $\begin{array}{c}26 \text { a 35 } \\
\text { anos }\end{array}$ & $\begin{array}{c}\text { Acima de } \\
35 \text { anos }\end{array}$ \\
\hline Número de Alunos & 186 & 76 & 23 \\
\hline$\%$ do Total & 65,26 & 26,67 & 8,07 \\
\hline
\end{tabular}

Fonte: Pesquisa de campo na Universidade (2009/2010).

A faixa etária inicial tem relação com as características do público atendido, pois partindo do princípio que na EJA predomina um público menos jovem optou-se por um recorte na faixa até 20 anos, para abarcar os jovens que, na prática, migraram do Ensino Médio regular. No caso dos universitários em final de curso, optou-se por dilatar a faixa até os 25 anos, de forma a atender os interesses da pesquisa. Assim, é sobre a especificidade do público jovem dessas faixas etárias que o presente artigo se concentra: 64 alunos do Ensino Médio da EJA e 186 alunos do Ensino Superior.

Apesar da abordagem do público jovem a partir dessa classificação etária, não se ignora as lições de Bourdieu (1983, p. 2) a respeito da complexidade dessa tomada:

As relações entre a idade social e a idade biológica são muito complexas. Se comparássemos os jovens das diferentes frações da classe dominante, por exemplo, todos os alunos que entram na École Normale, na ENA, etc., no mesmo ano, veríamos que estes 'jovens' possuem tanto mais dos atributos do adulto, do velho, do nobre, do notável, etc., quanto mais próximos se encontrarem do pólo do poder. Quando passamos dos intelectuais para os diretores-executivos, tudo aquilo que aparenta juventude, cabelos longos, jeans, etc., desaparece.

Há inúmeras outras perspectivas que podem ser utilizadas, de acordo com as áreas do conhecimento e/ou das opções ideológicas, de modo que a compreensão da juventude no século XXI não permite uma resposta simples:

A combinação entre distintas maneiras de enxergar a questão juvenil colabora para a tentativa de responder à pergunta sobre quando alguém deixa de ser jovem e atinge a vida adulta. Essa resposta, que não pode ser dada definitivamente, depende tanto dos indicadores relativos às transformações vividas pelo corpo jovem biológico quanto daquilo que se refere aos dados sociais objetivos e às representações que cada sociedade empresta ao conceito de jovem e juventude. (CARRANO, 2010, p. 157).

Logo, esclarece-se que não se trata de limitar a abordagem dos jovens, de forma unilateral, pela idade, pois isto não é suficiente para compreender a juventude em toda a sua complexidade contemporânea. Isso implicaria em ignorar o jovem enquanto sujeito do seu tempo, que é fortemente guiado pelas exigências da sua natureza orgânica ou pelos condicionamentos socioculturais, mas que também se esquiva do "destino" que a sociedade procura impor-lhe, reivindicando para si o protagonismo da sua própria história.

O recorte etário utilizado, portanto, representa apenas um recurso metodológico que permite uma aproximação para efeito de se considerar as percepções de um público jovem mais homogêneo em relação ao nível de escolaridade analisado, do ponto de vista etário, tendo em vista a sua relação com a educação e o trabalho, do que propriamente uma restrição à inclusão de outros indivíduos nessa categoria.

O estudo ora relatado procurou estabelecer nexos entre as percepções dos sujeitos que fazem um mesmo percurso formativo escolar com relação às suas angústias, anseios e reações diante da realidade mais ou menos comum que enfrentam na esfera escolar e profissional.

Em estudo sobre a produção teórica de Walter Benjamin a respeito da juventude, Pereira (2009, p. 244) esclarece que esse autor [...] 
atribui à juventude um espírito capaz de transformar a sociedade, porque vívido, pulsante, crítico, um espírito não conformado pelo desenvolvimento contínuo da história - leia-se, do progresso. O mundo que os adultos reservam aos mais jovens é, de acordo com o jovem filósofo, um mundo em franca decadência e estagnação, fruto de uma experiência que não produziu e não produz significado algum.

Talvez aí resida o segredo que faz a roda da sociedade girar: deparar-se, quando jovem, com um mundo inacabado ou, mais que isso, um mundo que não oferece respostas para as grandes questões suscitadas nessa fase da vida; quando muito, que se apresenta com evasivas e com respostas destituídas de sentido para as novas gerações.

Esse mundo "herdado", por ser hostil e inóspito aos jovens, desencadeia um tensionamento social permanente entre as gerações, de modo a situar a juventude no terreno das necessidades e das realizações:

Encontra-se aí o significado essencial que tem hoje 'ser jovem': é não ter nada a perder e ser para si mesmo apenas indefinidas possibilidades a realizar; é não ter propriedade, nem aquisições, nem interesses a defender [...] e, como consequência, não ter outro ponto de vista sobre o mundo que o de suas próprias exigências [...] (GORZ, 2009, p. 27).

Para usar expressões de Marx e Engels (1986), enquanto os trabalhadores são movidos pelo "reino da necessidade", o "reino da liberdade" vai se protelando indefinidamente. No caso em discussão, enquanto os jovens são copartícipes da produção da própria existência pelo trabalho, a fruição da fase juvenil da vida passa pela necessária mediação da escola no interesse da garantia do trabalho que, sob o sistema capitalista, depende da mercantilização da força de trabalho ou, em outras palavras, de atribuição de valor de troca ao próprio ser.

Nesse sentido, o estudo centrado nas relações da juventude com a escola e com o trabalho se mostra pertinente, tendo em vista o potencial de crítica que se apresenta mais latente nesse público, e as possibilidades de mudança que isso proporciona. Apresenta-se a seguir uma síntese do perfil dos dois públicos pesquisados:
Quadro 1 - Características dos alunos do Ensino Médio da EJA

- $41 \%$ (26) homens e 59\% (38) mulheres.

- $81 \%$ (52) estudaram em escola pública.

- $83 \%$ (53) pretendem continuar os estudos logo depois de conclusão do EM.

- Entre os pais dos alunos, 22\% (14) tinham Ensino Fundamental e 13\% (8) Ensino Médio, enquanto os demais não tinham concluído o Ensino Fundamental ou eram analfabetos.

- Entre as mães dos alunos, 20\% (13) tinham Ensino Fundamental, 20\% (13) Ensino Médio e 5\% (3) Ensino Superior, enquanto as demais não tinham concluído o Ensino Fundamental ou eram analfabetas.

- Condição de Trabalho:

- 41\% (26) desempregados, sendo 65\% (17) mulheres e $35 \%$ (9) homens.

- 19\% (12) têm trabalho informal.

- 9\% (6) não trabalham por opção.

- Somente 8\% (5) têm emprego com carteira assinada.

Fonte: Pesquisa de campo com alunos da EJA (2005/2006).

O que chama a atenção nos dados dos sujeitos jovens da EJA, marcados por um histórico de abandono da escola regular e reinserção a partir dessa modalidade específica, é que cerca de $20 \%$ (13) já tiveram oportunidade de estudar em escola particular, e que nem isso impediu uma história de descompasso na relação idade/série. A característica em comum é a da baixa escolaridade dos genitores, embora a situação seja um pouco melhor no caso das mães em comparação com os pais.

Outro aspecto interessante é que quatro em cada cinco têm interesse de continuar os estudos após a conclusão do Ensino Médio. Mesmo entre os universitários (Quadro 2) esse índice é alto - 64\% (83) entre os empregados e 70\% (39) entre os desempregados -, o que leva a crer pela indução social de um processo contínuo de educação formal, de modo que nem a conclusão de um curso superior é tida como suficiente para enfrentar os desafios da obtenção de emprego e renda na contemporaneidade. Esses dados surpreendem tendo em vista a ideia generalizada de que os jovens vêm perdendo o interesse pela escola.

Discutindo as relações entre o acesso dos jovens estudantes ao mercado de trabalho e a "valorização" da escola, Silva (2010, p. 248) conclui que 
[...] permanecer na escola parece significar aos jovens uma estratégia para enfrentar a competitividade no mercado de trabalho, seja por acreditarem que estão se capacitando para o atendimento às demandas do setor produtivo, seja por estarem interessados na aquisição de um diploma que os coloque num patamar diferenciado em relação a uma relevante parcela que não consegue, sequer, obter a escolaridade mínima.

Assim, o fato de que tanto os mais jovens quanto os menos jovens seguem valorizando a educação escolar remete à constatação de que a relação entre a cultura escolar e a cultura do trabalho, que a inserção social e a inserção profissional, são percebidas como importantes e continuam realimentando a escola como um valor indispensável na sociedade contemporânea. Se a educação continuada ganha espaço nas agendas econômicas e políticas das organizações e países, a educação escolar permanece como locus privilegiado da sua consecução.

No que se refere à situação de trabalho e renda, os dados demonstram que entre os jovens é alto o índice de desemprego, e mesmo os que trabalham estão submetidos a condições precárias de trabalho informal. Embora apenas 19\% (12) tenham declarado a condição de obtenção de renda pela via da informalidade laboral, é possível que esse número seja maior, visto que muitos se consideram autônomos, ainda que sem qualquer preocupação previdenciária. Apenas 8\% (5) declararam ter emprego com carteira assinada, o que por si só é coetâneo com o quadro de desestruturação da economia formal e de precarização das relações de trabalho, que vitima não só os jovens, mas principalmente eles.

Logo, da combinação das dificuldades tradicionais de inserção juvenil no mercado de trabalho, com o aprofundamento das restrições que decorrem de um problema econômico macroestrutural, mais o caráter excludente do sistema capitalista, que depende do barateamento dos custos para manter ou aumentar o lucro, ampliam-se as condições de precariedade que rondam a juventude e a sua transição da escola para o trabalho.

Segundo Rocha (2007), essas dificuldades têm implicações socioeconômicas importantes, haja vista que o alongamento e a incerteza que cercam esse período na vida dos jovens certamente geram algum mal-estar individual, que culmina rapidamente em mal-estar social caso envolva grande números de indivíduos. $\mathrm{Na}$ análise dessa estudiosa:

Parte das dificuldades e incertezas está associada a mudanças estruturais no mercado de trabalho, aos quais todos têm que se adaptar, mas são os jovens os que sofrem seu impacto mais direto: menos emprego tradicional, isto é, o emprego formal a tempo completo, único por toda a vida; mais ocupações temporárias intercaladas por períodos de inatividade e desemprego; mudança contínua dos requerimentos de qualificação e obsolescência rápida de competências, o que requer formação continuada e resulta em trajetórias profissionais não lineares. (ROCHA, 2007, p. 150-151).

Em um dos estudos que compreendem o mapeamento e a análise do trabalho informal na cidade de São Paulo, Pochmann (2001) faz uma esclarecedora análise da informalidade, mostrando que historicamente ela faz parte do sistema capitalista de produção e que, em São Paulo, decorre principalmente da ampliação do desemprego aberto, da redução do assalariamento em relação ao conjunto dos empregos e da geração de postos de trabalho precários. Segundo esse economista, há duas formas de inserção da força de trabalho: a diretamente necessária à acumulação capitalista e representada pelos postos de gestão, comercialização, produção e distribuição dos produtos e serviços; e aquela que abrange os segmentos ocupacionais que sobraram da inserção direta no sistema produtivo. É nessa segunda forma que se caracteriza o trabalho informal e, consequentemente, mais precário:

[...] o excedente de mão-de-obra é constituído por trabalhadores que sobraram das necessidades diretas do processo de acumulação de capital, sendo formado tanto pelo desemprego aberto (visível) como por trabalhadores que exercem atividades no máximo associadas ao capitalismo primitivo, mediante estratégias de sobrevivência (mercado de trabalho não-organizado). (POCHMANN, 2001, p. 20).

Contudo, as mudanças no padrão de produção e nas estratégias de competição entre as empresas estabeleceram novas formas de subemprego ou subcontratação, que ampliam o leque de ocupações e reconfiguram a informalidade, de modo que, ainda segundo Pochmann (2001, p. 20), “o segmento nãoorganizado poderia estar produzindo e reproduzindo 
não apenas formas ocupacionais do capitalismo primitivo, mas também vagas acionadas pelas grandes empresas".

Em estudo mais recente, com base na Pesquisa Nacional por Amostra de Domicílios (PNAD) de 2005, Pochmann (apud PORTAL VERMELHO, 2007) confirma que o trabalho sem carteira assinada não é mais um tipo de vínculo temporário ou que atinge apenas jovens ou pessoas com pouca escolaridade. Parece impor-se como um novo tipo de relação de trabalho, que engloba a contratação de consultores e prestadores de serviços, entre outros, mas sempre configurando situações em que as empresas economizam com encargos trabalhistas. Segundo ele, portanto, as pessoas nessa situação dificilmente serão absorvidas pelo mercado formal, pois o hábito que as empresas tinham de converter em formais os trabalhadores informais, tão logo as condições econômicas permitiam, algo comum no passado, já não ocorre com a mesma frequência.

Diante desse quadro ficam evidentes as motivações que levam os jovens a compreender a educação escolar como um investimento pessoal e a incorporação da formação continuada como estratégia para enfrentar o fantasma da informalidade e minimizar o risco de que ela seja a única via de inserção e até mesmo de permanência no mercado de trabalho.

Quadro 2 - Características dos alunos universitários

- Dos 186 pesquisados, 70\% (130) estavam empregados e 30\% (56) desempregados (voluntária ou involuntariamente).

- 34\% (63) homens e 66\% (123) mulheres.

- Entre os desempregados:

$-38 \%$ (21) homens e $62 \%$ (35) mulheres.

$-26 \%$ (15) estavam procurando emprego.

- Apenas 7\% (4) cursaram escola particular no Ensino Fundamental e 9\% (5) no Ensino Médio.

- 70\% (39) pretendem continuar estudos após a graduação.

- Entre os empregados:

$-33 \%$ (43) homens e $67 \%$ (87) mulheres.

- 27\% (35) cursaram escola particular no Ensino Fundamental e 53\% (69) no Ensino Médio.

- 64\% (83) pretendem continuar estudos após a graduação.

Fonte: Pesquisa de campo com alunos universitários (2009/2010).
Entre os jovens universitários, 30\% (56) encontravam-se desempregados, dos quais apenas uma quarta parte (15) declarou estar procurando trabalho, sendo significativa a manifestação de interesse pela dedicação exclusiva aos estudos nesse período. Assim, enquanto entre os jovens da EJA 9\% (6) declararam ter optado por não trabalhar, no caso dos universitários este índice é de 8\% (15). Embora a maioria dos jovens da EJA tenha interesse em continuar os estudos, sua condição representará um empecilho, primeiro porque entre os universitários empregados 53\% (69) cursaram Ensino Médio na rede privada e também porque se imagina que esse grupo tenha maiores condições de se manter sem trabalho e renda, inserindo-se no mercado de trabalho mais pela busca da independência em relação à família que pela necessidade financeira propriamente dita.

No caso dos jovens da EJA, uma possível associação dos estudos com o trabalho não pode considerar exclusivamente a busca da independência financeira em relação à família, posto que, diferentemente dos que estão atualmente na universidade (menos pobres e que tiveram melhor escolarização média), a análise da renda não se limita a sua dependência financeira em relação à família, senão da dependência da família em relação à sua renda.

Além disso, é preciso lembrar que o movimento em torno da revalorização da educação escolar, que resultou, por um lado, da associação entre escolarização e desenvolvimento econômico e, de outro, dos embates em torno da necessidade de mais investimentos nas políticas públicas educacionais, insere os jovens num contexto que permite múltiplas e complexas relações com o universo escolar, que se configura

[...] para muitos jovens por uma ambiguidade caracterizada pela valorização do estudo como uma promessa futura, uma forma de garantir um mínimo de credencial para pleitear um lugar no mercado de trabalho, ao mesmo tempo que supre uma possível falta de sentido que encontram no presente. (DAYRELL, 2009, p. 9).

O Brasil se caracterizou, historicamente, como uma nação que deu pouca atenção à universalização da educação escolar, de modo que além da inconsistência das políticas públicas destinadas à ampliação dos níveis educacionais, questões socioeconômicas relacionadas ao ingresso prematuro no 
mercado de trabalho contribuíram para que os níveis de escolarização da população jovem e adulta permanecessem baixos e condicionassem a vida futura de milhões de brasileiros.

A iniciação profissional em condições de inferioridade social não se restringe à primeira oportunidade de emprego, tendendo a se estender pela vida adulta, conforme experiência vivida pelos pais dos jovens que buscam a inserção. Levando- -se em consideração os dados de todos os jovens e adultos da EJA pesquisados, independentemente da idade, verifica-se que a inserção precoce e precária se reflete na vida presente e futura do trabalhador, reservando-lhe um conjunto de ocupações que tradicionalmente são pouco valorizadas e prestigiadas na sociedade capitalista, e que tende a se manter mais ou menos inalterável pelo resto da vida:

Quadro 3 - Ocupações de maior ocorrência entre os alunos-trabalhadores da EJA em dois momentos do seu histórico laboral: no início da vida profissional e por ocasião da pesquisa

\begin{tabular}{|l|c|l|}
\hline \multicolumn{1}{|c|}{ Quando se inseriu no mercado de trabalho } & $\begin{array}{c}\text { Em ordem de } \\
\text { frequência }\end{array}$ & \multicolumn{1}{|c|}{$\begin{array}{c}\text { Por ocasião desta pesquisa (anos depois, } \\
\text { conforme a situação do respondente) }\end{array}$} \\
\hline Ajudante de produção ou de serviços gerais & $1^{\circ}$ & Ajudante de serviços gerais \\
\hline Trabalhador doméstico como mensalista ou diarista & $2^{\circ}$ & Trabalhador doméstico como mensalista ou diarista \\
\hline Trabalhador rural & $3^{\circ}$ & Auxiliar ou operário semiqualificado da indústria \\
\hline Balconista ou atendente de comércio & $4^{\circ}$ & Vendedor externo/ambulante \\
\hline Auxiliar de escritório & $5^{\circ}$ & Mecânico ou eletricista \\
\hline Vendedor externo/ambulante & $6^{\circ}$ & Auxiliar de escritório \\
\hline
\end{tabular}

Fonte: Pesquisa de campo com alunos da EJA (2005/2006).

Assim, os frágeis mecanismos de ingresso na vida laboral, de fato, complexificam a relação dos jovens com o trabalho e com a educação. Um exemplo do dilema que os jovens enfrentam é o que se situa na decisão, para aqueles que têm o privilégio de não depender de renda própria para viver, entre: estudar ou trabalhar, estudar e trabalhar, não estudar nem trabalhar. Logo, ao mesmo tempo que o sistema produtivo sinaliza para os jovens a necessidade de escolarização e capacitação permanente, a condição econômica da família determina que seja priorizada a obtenção de emprego e renda, ainda que seja para assegurar a permanência na escola, uma vez que nem sequer essa possibilidade de combinar trabalho com estudo a maioria dos seus pais teve.

Mesmo assim, são inegáveis o esforço e os avanços decorrentes dos recentes investimentos e da maior presença dos jovens na escola, conforme demonstram os dados comparativos compilados pelo Instituto de Pesquisas Econômicas Aplicadas (IPEA), tendo como fonte a PNAD de anos selecionados.
Tabela 3 - Evolução das taxas de frequência à escola segundo faixas etárias e anos selecionados - em $\%$ da população etária

\begin{tabular}{c|r|c|c}
\hline Faixa Etária/Ano & $\mathbf{1 9 9 2}$ & $\mathbf{2 0 0 1}$ & $\mathbf{2 0 0 9}$ \\
\hline 7 aos 14 anos & 86,6 & 96,5 & 98,0 \\
\hline 15 aos 17 anos & 59,7 & 81,1 & 85,2 \\
\hline 18 aos 24 anos & 22,6 & 34,0 & 30,3 \\
\hline 25 aos 29 anos & 5,8 & 12,3 & 12,2 \\
\hline
\end{tabular}

Fonte: Adaptados da PNAD, apresentada no Comunicado n. 66 do IPEA (2010).

É natural a ocorrência de taxas proporcionalmente menores na mesma medida em que se verifica o avanço etário, mas chama a atenção o fato de a taxa do público que tem 18 anos ou mais não ter melhorado na última década. Depois de uma expansão significativa no período de 1992 a 2001, tanto para o público de 18 a 24 anos (de 22,6\% para $34 \%$ ) quanto para o de 25 a 29 anos (de 5,8\% para $12,3 \%$ ), o mesmo não se verificou no período de 2001 a 2009, com a permanência da mesma taxa para o público de 25 a 29 anos, e redução do atendimento do público de 18 a 24 anos (de $34 \%$ para $30,3 \%$ ).

Ainda que se tenha verificado uma ampliação absoluta da população nessa faixa etária, os dados 
revelam que a política pública não tem conseguido acolher esse público e sequer acompanhado o seu crescimento vegetativo.

Tabela 4 - Evolução da população brasileira na faixa etária dos 15 aos 24 anos e participação na população total, em anos selecionados

\begin{tabular}{c|c|c|c}
\hline \multicolumn{1}{c|}{ Ano } & 1991 & 2000 & 2010 \\
\hline Em número de pessoas & 28.582 .350 & 34.081 .330 & 34.236 .064 \\
\hline Em \% da população total & 19,5 & 20,07 & 17,95 \\
\hline
\end{tabular}

Fonte: Censos demográficos dos anos selecionados (IBGE).

Outro aspecto a ser considerado é o que demonstra o desalento e a marginalidade socioeconômica de um grande grupo de jovens que não estão hoje nem estudando nem trabalhando. É isso o que acaba de revelar o estudo realizado pelo Instituto de Estudos Sociais e Políticos da Universidade Estadual do Rio de Janeiro, a partir dos dados do Censo 2010. Segundo os dados, perto de $20 \%$ dos jovens brasileiros, com idade entre 18 e 25 anos, não estão estudando, trabalhando ou mesmo procurando emprego. Trata-se de um contingente de mais de 5,3 milhões de pessoas, à margem da População Economicamente Ativa (PEA). Os motivos para estarem fora da escola e sem trabalho são muitos e vão desde a evasão escolar e o desalento, passando pela gravidez precoce e o envolvimento com o crime. (O Estado de São Paulo, 2012). Isso não quer dizer que efetivamente não estejam trabalhando e obtendo renda pelas franjas da economia formal, posto que a vulnerabilidade é tamanha e se manifesta desde a mais tenra idade, de maneira que "viver" e "trabalhar" transformam-se em uma coisa só.

Essa constatação revela a gravidade da questão. Mas a análise exige maior aprofundamento, em especial quando se percebe uma estreita relação entre a educação e as condições de acesso ao mercado de trabalho na percepção dos sujeitos jovens abordados nesta pesquisa, conforme demonstram as respostas a seguir, dadas por eles próprios.
Quadro 4 - Opiniões dos jovens estudantes sobre as contribuições da educação para a vida profissional

- Entre os jovens da EJA:

- 33\% (21) acham que a educação melhora as condições de emprego.

- 27\% (17) acham que a educação melhora as condições de empregabilidade (obtenção de emprego).

- Entre os jovens universitários empregados:

$-25 \%$ (32) dizem que melhora a empregabilidade.

- 29\% (38) acham que melhora a qualificação para o trabalho.

- 16\% (21) entendem que melhoram as condições de emprego e renda.

$-13 \%$ (17) dizem que potencializa a carreira profissional.

- 16\% (21) entendem que representa o início, mas não é tudo.

- Entre os jovens universitários desempregados:

$-25 \%$ (14) dizem que melhora a empregabilidade.

- 24\% (13) acham que melhora a qualificação para o trabalho.

$-15 \%$ (8) entendem que melhoram as condições de emprego e renda.

$-13 \%$ (7) dizem que potencializa a carreira profissional.

- 13\% (7) entendem que representa o início, mas não é tudo.

Fonte: Pesquisa de campo com estudantes da EJA (2005-2006) e universitários $(2009 / 2010)$.

O quadro demonstra que as respostas se aproximam nos três segmentos pesquisados, com exceção de um detalhe importante: embora tanto os jovens da EJA quanto os universitários acreditem na melhoria da empregabilidade pela via da educação escolar, mais que o dobro dos primeiros $(33 \%$, ou 21 estudantes) atribui à educação uma importância maior na definição do emprego e renda, em comparação com os demais - 15\% (8) no caso dos universitários desempregados e $16 \%$ (21) no caso dos universitários empregados.

Talvez o potencial explicativo dessa maior crença dos jovens da EJA na inserção profissional em condições mais vantajosas esteja no fato de que entre eles o desemprego é maior e na hipótese de que suas condições financeiras são mais precárias. Para checar essa hipótese, recorreu-se ao nível de renda dos dois grupos: 
- entre os jovens da EJA, 29\% (19) têm renda inferior a 1 salário mínimo e $63 \%$ (40) entre 1 e 3 salários mínimos;

- entre os universitários empregados, 39\% (51) têm renda de até 1 salário mínimo e $54 \%$ (70) entre 1 e 3 salários mínimos.

$\mathrm{O}$ fato de os jovens da EJA terem declarado níveis de renda pouco acima dos universitários não permite concluir que eles têm condição financeira melhor, em especial porque um em cada três universitários possui outras fontes de renda (pais, cônjuge, pensão, aluguel, bolsa de estudos). Logo, os jovens da EJA depositam na educação a esperança de contribuição para uma inserção profissional mais qualitativa, possivelmente em ocupações que se distanciem da sua experiência pretérita e atual de subemprego e precariedade.

A condição de inserção profissional precoce, declaradamente maior entre os estudantes da EJA, simultaneamente ao abandono ou postergação da escolarização fundamental, contribui para que a escola (ou falta dela) seja alçada à condição de responsável pelas condições de precariedade. E isso ocorre naturalmente no âmbito da sociedade capitalista, conforme já constatava Turgot:

$\mathrm{O}$ trabalhador simples, que depende apenas de suas mãos e sua indústria, não tem senão a parte de seu trabalho de que pode dispor para os outros. Vende-a a um preço maior ou menor; mas esse preço alto ou baixo não depende apenas dele; resulta de um acordo que fez com a pessoa que o emprega. Esta lhe paga o menos possível, e, como pode escolher entre muitos trabalhadores, prefere o que trabalha por menos. Os trabalhadores são por isso obrigados a reduzir seu preço em concorrência uns com outros. Em toda espécie de trabalho deve acontecer, e na realidade acontece, que os salários do trabalhador se limitam apenas ao que é necessário à mera subsistência. (apud HUBERMAN, 1980, p. 212).

Isso não quer dizer que os mais bem escolarizados estejam isentos dessa precariedade salarial e laboral, em especial quando o capitalismo passa a experimentar crises cíclicas e cada vez mais agudas. Já no século XIX os economistas clássicos interpretavam como natural que os salários fossem estabelecidos "pelo mercado", como se ele fosse um ente que se impõe e que independe das relações constru- ídas no cotidiano da existência, conforme se depreende dos argumentos de Ricardo:

O preço do mercado do trabalho é o preço realmente pago por ele, resultado da operação natural da proporção entre a oferta e a procura: o trabalho é caro quando escasso, e barato quando abundante. Por mais que o preço do mercado do trabalho se possa desviar de seu preço natural, ele tem, como as mercadorias, a tendência de se conformar a ele. (apud HUBERMAN, 1980, p. 213).

Assim compreendido, abre-se espaço para que a mão de obra seja facilmente alçada à condição de vilã da economia, o que se forja no discurso que aponta como causas dos altos custos de produção a falta de qualificação e a baixa produtividade, passando-se a responsabilizar os trabalhadores pelo desaquecimento da economia e pelo mau funcionamento do sistema.

Feita essa rápida retomada dos fundamentos que supervalorizam a "mão invisível do mercado", deve-se reconhecer que, hoje, conforme atestam as respostas dos próprios estudantes pesquisados, melhores patamares de educação formal, de certa forma, ampliam as possibilidades de "sobrevivência" em tempos de crise.

Segundo o estudo Tendências do Emprego Juvenil (ILO, 2010), embora os empregos juvenis no mundo tenham se ampliado de 528,8 milhões, em 1991, para uma projeção de 539,8 milhões, em 2011, esse crescimento não tem sido suficiente para acompanhar o aumento dessa população etária, observando-se uma queda na taxa de empregos juvenis em relação ao total dos empregos de $52,5 \%$ para $44,3 \%$. No mesmo período, o desemprego juvenil subiu de $11,7 \%$ para $12,7 \%$, sendo ainda maior na América Latina e no Caribe (em torno de 16\%).

$\mathrm{Na}$ pesquisa com os jovens universitários e da EJA, também foi solicitado aos estudantes que manifestassem suas opiniões quanto às causas do desemprego na sociedade. A tabela a seguir apresenta um resumo das principais respostas.

\footnotetext{
${ }^{1}$ Esta expressão se incorporou ao discurso neoliberal para indicar o poder que o próprio mercado (pessoas e organizações) tem, sem a tutela do Estado, de resolver seus problemas e, em última análise, de maximizar suas receitas. Embora haja controvérsia sobre a sua origem, a maioria dos autores atribui ao filósofo e economista escocês Adam Smith (1723-1790), autor de A Riqueza das Nações, o pioneirismo de utilizar a expressão, ainda que a usasse inicialmente como "mão invisível", tendo sido acrescentada a palavra "do mercado" mais tarde (BORGES, 2006).
} 
Tabela 5 - Principais causas estruturais do desemprego segundo a percepção de jovens da EJA e universitários - em \% de ocorrências e possibilidade de múltipla resposta

\begin{tabular}{l|c|c|c}
\hline \multicolumn{1}{c|}{ Causa } & Jovens da EJA & Universitários Empregados & Universitários Desempregados \\
\hline Baixa qualificação & 53 & 71 & 55 \\
\hline Falta de experiência & 33 & 4 & 4 \\
\hline Falta de vagas/oportunidades & 25 & 17 & 15 \\
\hline Governo & 5 & 6 & 13 \\
\hline
\end{tabular}

Fonte: Pesquisa de campo com alunos da EJA (2005/2006) e universitários (2009/2010).

Embora os três grupos tenham mencionado a baixa qualificação como causadora do desemprego, o que replica o discurso estratégico do sistema produtivo presente nos noticiários, chama a atenção que esta causa seja mais apontada pelos universitários empregados que pelos desempregados e pelos jovens da EJA. Assim, as respostas ganham mais sentido quando relacionadas à condição dos respondentes, de modo que mesmo para quem já está empregado o fator continua sendo importante, ainda que perca em dramaticidade.

Quanto à falta de vagas/oportunidades de trabalho e falta de experiência, a menção é maior entre os alunos da EJA, embora também apareça entre os universitários. No que se refere à culpa do governo (em relação às políticas públicas), apesar de aparecer nos três segmentos, é mais citada pelos universitários desempregados, possivelmente porque no seu caso a frustração é maior, tendo em vista a permanência da condição de desemprego mesmo depois de três ou quatro anos na universidade.

No geral, parece que os fatores mais lembrados pelos jovens repercutem o discurso quase hegemônico na sociedade do século XXI, bastante marcada pela introdução do sistema meritocrático do sistema produtivo. A internalização, no plano individual, das pseudossoluções para os descompassos do modo de produção (mais candidatos que vagas de emprego, por exemplo), inibe as ações do interesse da coletividade e dissimula as verdadeiras causas dos problemas estruturais, o que acaba por atribuir aos indivíduos a culpa e a necessária tomada de decisão para a solução, também no plano individual. Isso introduz no plano das relações de trabalho o acirramento da competição entre os trabalhadores, enfraquecendo-os enquanto classe e fortalecendo os empregadores. No caso dos jovens, os efeitos podem ser ainda mais danosos, dado o período de ansiedade próprio relacionado ao esforço para a inserção no mercado de trabalho.

Segundo estudo de Araújo (1999, p. 15), mais do que uma exigência dos novos modelos de trabalho e de configuração organizacional, as supostas "novas características pessoais", valorizadas e promovidas pela empresa, parecem ter como ideia de fundo a possibilidade de intensificação do ritmo de trabalho e a apropriação do saber tácito, mediados pelas novas técnicas organizacionais:

A nova racionalidade da empresa admite e incorpora certos conflitos e críticas, aproveitando-se dos mesmos para tentar aumentar a sua produtividade e eliminar a dissidência. A empresa parece desvalorizar o trabalhador que se submete e produz pouco e aquele que só reclama sem apresentar solução. A empresa promoveu a substituição da lógica da produção fordista calcada no cálculo e na obediência estreita de tempos e movimentos, pela lógica da flexibilidade que valoriza certas características pessoais, a qualificação tácita e o trabalho real ao invés da qualificação formal e o trabalho prescrito.

Assim, parece que, embora a frequência à escola tenha melhorado e os estudantes continuem valorizando-a como contributiva para a obtenção de renda, as condições em que essa inserção ocorre continuam marcadas, e agora mais do que antes, pelas "necessidades" de atendimento às demandas do sistema produtivo, seja quantitativamente, o que impacta nas condições de oferta de trabalho, seja qualitativamente, pelas condições em que se dão tais ofertas.

\section{Considerações finais}

Este artigo apresentou os resultados de investigações realizadas com jovens estudantes em duas 
etapas distintas da educação escolar pública: do Ensino Médio em escola de EJA e do Ensino Superior.

Mesmo recortando-se o universo pesquisado e concentrando-se sobre uma amostra de 64 alunos na faixa etária até os 20 anos, no caso do Ensino Médio da EJA, e de 186 alunos na faixa até 25 anos, no caso do Ensino Superior, considera-se que tal classificação etária serviu apenas para efeito de concentração da análise sobre um público mais homogêneo em relação às condições de escolarização e relações com o mercado de trabalho.

Os resultados da pesquisa mostram que o público jovem que frequenta a escola corresponde a uma parcela restrita da população jovem total, ficando em torno de $30 \%$ no caso dos brasileiros na faixa entre os 18 e 24 anos.

A pesquisa também revela que a participação feminina se mantém na casa dos $65 \%$ tanto no total de estudantes das duas modalidades quanto no estrato que considera isoladamente os empregados e desempregados. Há alguma indicação de que a maior escolaridade reduz a participação feminina no grupo dos desempregados, mas não há dados suficientes para esta afirmação.

Um dado significativo é o da declaração da maioria dos jovens, de que pretendem continuar os estudos tão logo concluam a atual etapa escolar. Se essa declaração não estiver influenciada por outros fatores, equivocado é o consenso de que a educação escolar vem perdendo sentido para os jovens, a menos que essa resposta tenha outras explicações, como a forte sinalização do mercado quanto à necessidade de qualificação educacional formal, pelo menos no âmbito do sistema produtivo. Ainda assim, o significado nunca é neutro, e a importância atribuída à escola, mesmo que mediada pelo mercado de trabalho, não deixa de representar um interesse para a realização da existência, tanto no plano da materialidade quanto da subjetividade jovem, mas esta é uma questão a ser aprofundada em outras investigações.

Por fim, considerando que o estudo da relação dos jovens e adultos trabalhadores com a educação e com o trabalho faz parte de um esforço de pesquisa empreendido de forma ininterrupta nos últimos 15 anos, deixa-se aqui registrado que parte dos dados deste artigo tem sido divulgada em eventos da área de Educação, Educação de Jovens e Adultos e Educação e Trabalho.

\section{Agradecimentos}

Aos estudantes que concordaram em participar da pesquisa; à Universidade Estadual do Centro Oeste (UNICENTRO) pelo credenciamento e apoio aos projetos de pesquisa que deram origem a este artigo; à Fundação Araucária, pela concessão de bolsa de iniciação científica à aluna Sonia de Fátima Loures, que colaborou em uma das etapas do estudo; e à Coordenação de Aperfeiçoamento de Pessoal de Nível Superior (CAPES) pela concessão de bolsa nos últimos dois anos de investigações junto ao Programa de Pós-Graduação em Educação da Universidade Federal do Paraná.

\section{Referências}

ARAÚJO, Ronaldo M. de L. As novas qualidades pessoais requeridas pelo capital. In: Trabalho \& Educação, Belo Horizonte, n. 5, jan./jun. 1999.

BORGES, R. A esquerda do pai do capitalismo. Jornal Valor Econômico, 11 ago. 2006, p. 14.

BOURDIEU, Pierre. Entrevista: A "juventude" é apenas uma palavra. In: Questões de sociologia. Rio de Janeiro: Marco Zero, 1983, p. 112-121.

CARRANO, Paulo C. R. O ensino médio na transição da juventude para a vida adulta. In: FERREIRA, Cristina A. et. al. (org.). Juventude e iniciação científica: políticas públicas para o ensino médio. Rio de Janeiro: EPSJV, UFPR, 2010.

DAYRELL, Juarez. Apresentação da série Juventude e escolarização: os sentidos do Ensino Médio. In: Juventude e escolarização: os sentidos do Ensino Médio. Brasília: MEC / Secretaria de Educação à Distância, Nov. 2009, Ano XIX, Boletim 18.

O ESTADO DE SÃO PAULO. Caderno Economia \& Negócios. "Nem nem": legião que não estuda nem trabalha. 21 out. 2012. Disponível em: <http://economia. estadao.com.br/noticias/economia,nem-nemlegiao-quenao-estuda-nem-trabalha, 131598,0.htm>. Acesso em: 30 nov. 2012.

GORZ, André. O envelhecimento. Tempo soc., 2009, vol. 21, n. 1, p. 15-34.

HUBERMAN, Leo. História da riqueza do homem. 16. ed. Rio de Janeiro: Zahar, 1980. 
IBGE - Instituto Brasileiro de Geografia e Estatística. Censos Demográficos - anos selecionados [1991 - 2000 - 2010]. Brasília. Disponível em: <http://www.ibge.gov.br/ home/mapa_site/mapa_site. php\#populacao $>$. Acesso em: 21 set. 2012.

ILO - INTERNACIONAL LABOUR OFFICE. Global employment trends for youth. Geneva: August 2010.

IPEA. Comunicado n. 66. Situação da Educação Brasileira: Avanços e Problemas. Brasília: 18 dez. 2010.

MARX, Karl; ENGELS, Friedrich. O manifesto do partido comunista. 6. ed. São Paulo: Global, 1986.

PEREIRA, Marcelo de A. Juventude, experiência e conhecimento em Walter Benjamin: para um novo saber da educação. In: Currículo sem Fronteiras, Santa Maria - RS, UFSM, v. 9, n.2, p. 242-257, Jul./Dez. 2009.

POCHMANN, Márcio. O excedente de mão de obra no município de São Paulo. In: JACOBSEN, Kjeld; Martins, Renato; DOMBROWSKI, Osmir (org.). Mapa do trabalho informal - Perfil socioeconômico dos trabalhadores informais na cidade de São Paulo. São Paulo: Fundação Perseu Abramo, 2001. Disponível em: <http://fpa.org.br/ uploads/mapa_do_trabalho_informal.pdf $>$. Acesso em: 27 dez. 2012.

PORTAL VERMELHO. Trabalho autônomo avança e eleva nível de informalidade. São Paulo: Central dos Trabalhadores e Trabalhadores do Brasil, 2007. Disponível em: $<$ http://www.vermelho.org.br/ro/noticia.php?id_noticia= 18105\&id_secao=2>. Acesso em: 25 set. 2012.

ROCHA, Sonia. O mercado de trabalho e a inserção produtiva dos jovens. In: Análise da Pesquisa Nacional por Amostra de Domicílios - PNAD: 2005. - Mercado de trabalho - Brasília: MTE, AI, 2007.

SILVA, Mariléia M. da. Redes de relações sociais e acesso ao emprego entre os jovens: o discurso da meritocracia em questão. In: Educ. Soc., Campinas, v. 31, n. 110, p. 243260, jan./mar. 2010.

Data de Submissão: dezembro de 2012

Data de Aprovação: abril de 2013 